\title{
Do team and task performance improve after training situation awareness? A randomized controlled study of interprofessional intensive care teams
}

\author{
Karin Jonsson ${ }^{1 *}$, Christine Brulin², Maria Härgestam² ${ }^{2}$, Marie Lindkvist ${ }^{3}$ and Magnus Hultin ${ }^{4}$ (D)
}

\begin{abstract}
Background: When working in complex environments with critically ill patients, team performance is influenced by situation awareness in teams. Moreover, improved situation awareness in the teams will probably improve team and task performance. The aim of this study is to evaluate an educational programme on situation awareness for interprofessional teams at the intensive care units using team and task performance as outcomes.

Method: Twenty interprofessional teams from the northern part of Sweden participated in this randomized controlled intervention study conducted in situ in two intensive care units. The study was based on three cases (cases 0,1 and 2 ) with patients in a critical situation. The intervention group $(n=11)$ participated in a two-hour educational programme in situation awareness, including theory, practice, and reflection, while the control group $(n=9)$ performed the training without education in situation awareness. The outcomes were team performance (TEAM instrument), task performance (ABCDE checklist) and situation awareness (Situation Awareness Global Assessment Technique (SAGAT)). Generalized estimating equation were used to analyse the changes from case 0 to case 2, and from case 1 to case 2.

Results: Education in situation awareness in the intervention group improved TEAM leadership $(p=0.003)$, TEAM task management $(p=0.018)$ and TEAM total $(p=0.030)$ when comparing cases 1 and 2 ; these significant improvements were not found in the control group. No significant differences were observed in the SAGAT or the ABCDE checklist.

Conclusions: This intervention study shows that a 2-h education in situation awareness improved parts of team performance in an acute care situation. Team leadership and task management improved in the intervention group, which may indicate that the one or several of the components in situation awareness (perception, comprehension and projection) were improved. However, in the present study this potential increase in situation awareness was not detected with SAGAT. Further research is needed to evaluate how educational programs can be used to increase situation awareness in interprofessional ICU teams and to establish which components that are essential in these programs.

(Continued on next page)
\end{abstract}

\footnotetext{
* Correspondence: karin.jonsson@umu.se

'Department of Nursing and Department of Surgical and Perioperative

Sciences, Anesthesiology and Critical Care Medicine, Umeå University, S-901

87 Umeå, Sweden

Full list of author information is available at the end of the article
}

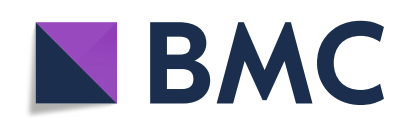

(c) The Author(s). 2021 Open Access This article is licensed under a Creative Commons Attribution 4.0 International License, which permits use, sharing, adaptation, distribution and reproduction in any medium or format, as long as you give appropriate credit to the original author(s) and the source, provide a link to the Creative Commons licence, and indicate if changes were made. The images or other third party material in this article are included in the article's Creative Commons. licence, unless indicated otherwise in a credit line to the material. If material is not included in the article's Creative Commons licence and your intended use is not permitted by statutory regulation or exceeds the permitted use, you will need to obtain permission directly from the copyright holder. To view a copy of this licence, visit http://creativecommons.org/licenses/by/4.0/ The Creative Commons Public Domain Dedication waiver (http://creativecommons.org/publicdomain/zero/1.0/) applies to the data made available in this article, unless otherwise stated in a credit line to the data. 
(Continued from previous page)

Trial registration: This randomized controlled trial was not registered as it does not report the results of health outcomes after a health care intervention on human participants.

Keywords: Critical care, Interdisciplinary health team, Leadership, Patient safety, Simulation training, Situation awareness, Team performance

\section{Introduction}

Preventable adverse events are common in intensive care units (ICU), both in Sweden [1] and globally [2]. Internationally, about $34 \%$ of patients in the ICU are affected by adverse events, and $60 \%$ of those events are avoidable [3]. Several studies have reported shortcomings in intensive care teamwork in respect to team leadership [4] and patient outcomes [5]. Fewer studies have focused on ICU teams' situation awareness (SA) in order to improve team and task performance [6]. SA is described as being able to perceive what is going on (perception), to assess and interpret the situation (comprehension) and to project into the future (projection) [7].

SA is important in order to make the right decision at the right time. Attention to and knowledge of SA increase safety and reduce errors in high-risk organizations [8]; recently, Brennan [9] reported that such knowledge has improved patient safety in healthcare systems. It is clear that teamwork in the ICU depends on individuals' coordinated actions and understanding of tasks, including collective cognitive structures such as shared mental models to optimize care [10]. Similarity, SA in teams has been shown to influence mental models and, consequently, decision-making processes [11, 12]. However, the role of SA in teams working in the ICU has been sparsely investigated and requires further examination.

Shared SA is a precursor of decision-making and is necessary for team coordination and performance [13]. Specific and targeted educational programmes to increase SA have been developed for aviation, the military [11], the police [14] and operating room personnel [15]. Education in SA has been suggested to be effective for the detection of patient deterioration [16]. However, a recent systematic review on educational interventions to enhance SA in healthcare showed that only two of the 39 included studies had an ICU context and neither was randomized; furthermore, only four of these studies had a specific focus on SA in the interventions [17]. Thus, specific randomized intervention studies evaluating SA education in respect to non-technical skill (NTS) outcomes such as team and task performance within healthcare are still lacking.

Team and task performance in well-functioning teams are essential for high-quality care in critical care settings [2]. Trauma teams with leaders that can communicate SA and encourage backup behaviours are able to perform better teamwork [18]. Team performance, as measured by leadership, team work and task management [19] in relation to SA, has been sparsely investigated. In a recent review, Schulz et al. [20] pointed out the importance of $\mathrm{SA}$ in the decision-making process, which affects team performance [21]. However, less attention has been paid to the association between SA and task performance.

In sum, SA plays an important role in improving the efficiency of intensive care teams. We hypothesized that a brief educational programme for intensive care teams with a focus on SA in a critical situation would improve teamwork outcomes such as: (1) SA; (2) overall team performance including leadership, teamwork and task management; and (3) task performance. Thus, this randomized intervention study aimed to evaluate an educational programme in SA for intensive care teams using team and task performance as outcomes.

\section{Methods}

This randomized controlled intervention study evaluated an ICU team training educational programme that focused on SA with in situ simulations, using questionnaires and video-recorded observations. The study was performed in two hospitals ( $\mathrm{H} 1$ and $\mathrm{H} 2)$ in the northern part of Sweden.

\section{Participants}

Enrolled nurses (ENs), critical care nurses (CCRNs) and physicians (MDs) working at two different ICU during the spring of 2017 were invited to participate in this study. A total of 215 individuals (H1 $n=104$ vs. H2 $n=$ 111) were employed at the studied ICUs. At the time of this study, 176 individuals were active in the work at the ICU and were thus invited to participate.

After the baseline session, referred to herein as session one (case 0$)$, all personnel ( $n=105,26$ teams) from the baseline session were invited to participate in the intervention. Before organizing the follow-up - that is, session two (cases 1 and case 2) - the teams were stratified by hospital; thereafter, the participants at each hospital were randomized by drawing of lots into a control or intervention group (Fig. 1). In all, 75 of the 105 invited individuals participated in the follow-up, with nine teams in the control group and 11 teams in the intervention group. The reasons given for dropping out of the follow-up were mainly scheduling difficulties and high 


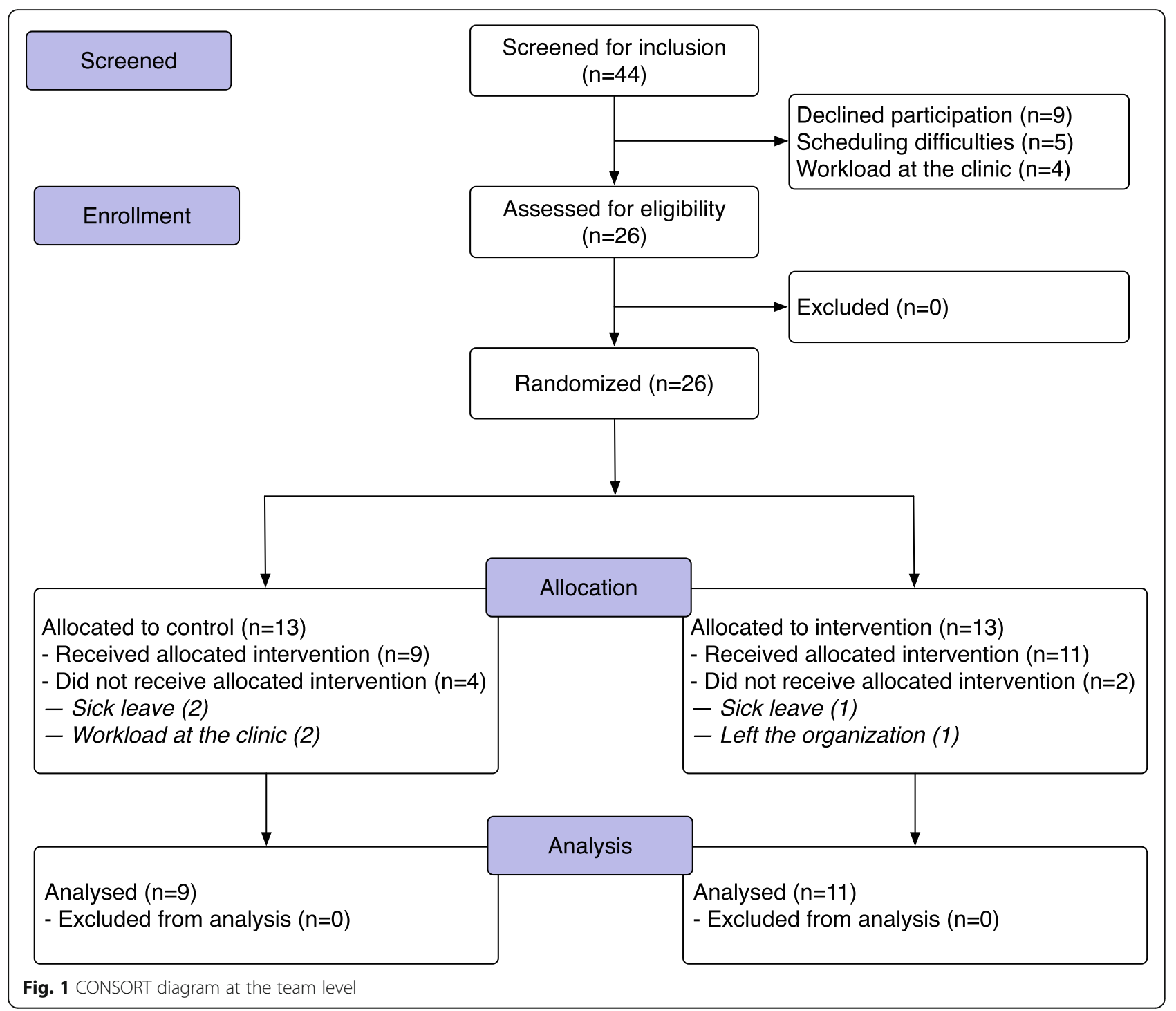

workload at the clinics. The follow-up included 20 teams. Most participants were female (59 of 75), and the participants' ages ranged from 28 to 64 years (Table 1 ). Thirteen teams consisted of four individuals and seven teams consisted of three or five individuals. All teams included at least one of each of the listed professionals, except for one team that lacked an EN.

Information about the study was provided to the participants in both written and verbal form at site meetings and by mail. Although participation in this study was voluntary, the team training sessions were mandatory for all employees. CONSORT reporting of trials was used. Consent for the project was obtained from the clinic management, and the study was approved by the Regional Ethical Review Board in Northern Sweden (April 7, 2016, Decision No. 2016-54-31 M). Informed consent was obtained from all participants.

\section{Setting}

As mentioned earlier, the setting was in situ team training at two ICUs in two hospitals. The team training was performed using a patient simulator, Laerdal SimMan (3G). For standardization of the sessions, the patient simulator was pre-programmed with timed interventions for similar responses to performed actions. All other equipment was the usual equipment from the clinical environment. Two high-definition cameras were mounted to record the scenarios.

\section{Procedure and team training for the intervention and control group}

Session one was performed over 11 weeks during the spring of 2017. The same teams were then scheduled for session two, the follow-up training session including the intervention, during 8 weeks in autumn 2017 (Fig. 2). 
Table 1 Background characteristics of participants and teams in session two. Age and prior work experience are expressed as mean (standard deviation). Remaining variables are binary. At the team level, the proportion of participants in the teams belonging to the indicator category are shown as mean (standard deviation)

\begin{tabular}{|c|c|c|c|c|c|c|}
\hline \multirow[t]{3}{*}{ Characteristics } & \multicolumn{3}{|l|}{ Individual level } & \multicolumn{3}{|l|}{ Team level } \\
\hline & $m(s d)$ & & & $m(s d)$ & & \\
\hline & Control $(n=32)$ & Intervention $(n=43)$ & $p$ (t-test) & Control $(n=9)$ & Intervention $(n=11)$ & $p$ (t-test) \\
\hline Age & $45.8(9.7)$ & $45.9(9.5)$ & .978 & $46.2(5.86)$ & $45.9(5.82)$ & .908 \\
\hline \multirow[t]{3}{*}{ Prior work experience } & $16.6(9.9)$ & $18.3(10.1)$ & .476 & $17.0(6.17)$ & $18.4(5.35)$ & .593 \\
\hline & $n(\%)$ & & & $m(s d)$ & & \\
\hline & Control & Intervention & $p\left(X^{2}\right)$ & Control & Intervention & $p(t$-test $)$ \\
\hline Gender female & $23(72)$ & $36(84)$ & .216 & $0.72(0.13)$ & $0.83(0.21)$ & .209 \\
\hline Gender male & $9(28)$ & $7(16)$ & - & $0.28(0.13)$ & $0.17(0.20)$ & .209 \\
\hline Hospital 1 & $20(63)$ & $19(44)$ & .116 & $0.66(0.50)$ & $0.45(0.52)$ & .369 \\
\hline Hospital 2 & $12(37)$ & $24(56)$ & - & $0.33(0.50)$ & $0.54(0.52)$ & .369 \\
\hline Profession EN & $10(31)$ & $12(28)$ & .879 & - & - & - \\
\hline Profession CCRN & $13(41)$ & $20(46)$ & - & - & - & - \\
\hline Profession MD & $9(28)$ & $11(26)$ & - & - & - & - \\
\hline MD at specialist level & $7(78)$ & $8(73)$ & .795 & $0.78(0.44)$ & $0.73(0.47)$ & .808 \\
\hline Former courses & $18(56)$ & $33(77)$ & .060 & $0.55(0.26)$ & $0.76(0.18)$ & $.041^{*}$ \\
\hline Former experience CRM & $15(47)$ & $23(54)$ & .571 & $0.45(0.30)$ & $0.53(0.23)$ & .452 \\
\hline Former experience debriefing with video & $14(44)$ & $18(42)$ & .870 & $0.42(0.24)$ & $0.41(0.20)$ & .964 \\
\hline Former education leadership & $5(16)$ & $11(26)$ & .298 & $0.16(0.15)$ & $0.27(0.22)$ & .201 \\
\hline Former education communication & $8(25)$ & $12(28)$ & .778 & $0.24(0.27)$ & $0.28(0.18)$ & .730 \\
\hline Former team training with video & $21(66)$ & $27(63)$ & .800 & $0.63(0.27)$ & $0.62(0.31)$ & .968 \\
\hline Former team training no video & $26(81)$ & $37(86)$ & .575 & $0.79(0.29)$ & $0.88(0.25)$ & .437 \\
\hline Positive attitude re value of team training & $30(94)$ & $37(86)$ & .285 & $0.94(0.13)$ & $0.85(0.18)$ & .274 \\
\hline Perception of daily frequency of team work & $29(91)$ & $41(95)$ & .417 & $0.91(0.19)$ & $0.95(0.10)$ & .483 \\
\hline Perception of good quality of team work & $30(94)$ & $41(95)$ & .630 & $0.94(0.11)$ & $0.92(0.15)$ & .661 \\
\hline
\end{tabular}

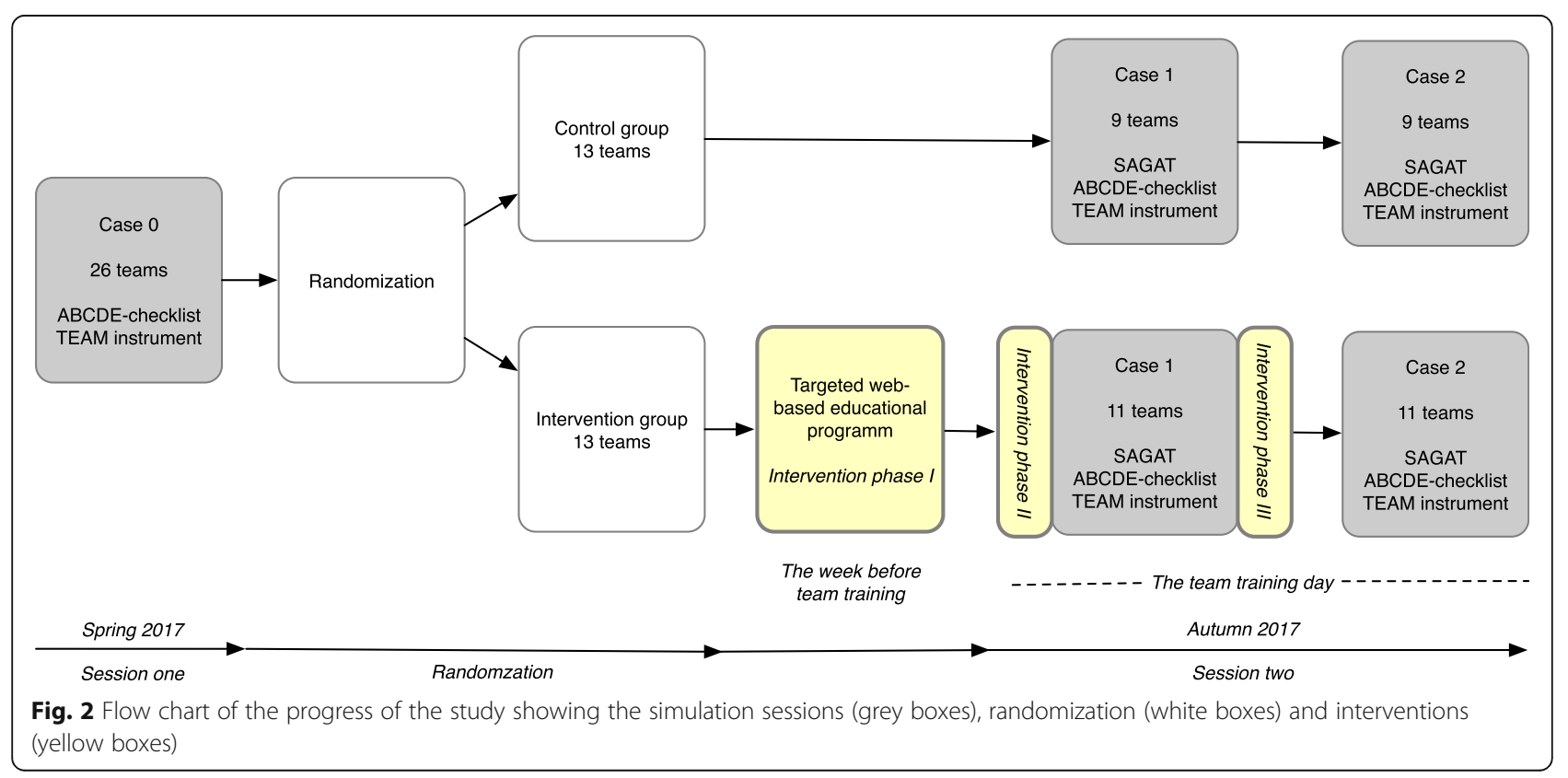


The baseline data from session one were analysed separately and recently published [21]. In session two, the participants trained using two different cases (case 1 and case 2). All three scenarios were designed to last $15-20 \mathrm{~min}$ and were first tested on physicians and CCRNs/ registered nurse anesthetists not involved in the study.

Six instructors at each hospital facilitated the training sessions, two at a time. Between session one and session two, the instructors $(n=6)$ in the intervention group received a one-day educational session including SA and theories of didactics and experiential learning [22]. Before the start of both sessions one and session two, all participants received a short pre-briefing that focused on the goals of the training and were asked to act as if they were experiencing an ordinary day at work. The participants were also introduced to the training room, facilities and patient simulator. The patients in the cases were in directly life-threatening situations. Case 0 suffered from several airway problems, case 1 suffered from obstructive pulmonary disease and case 2 was experiencing severe septic shock.

\section{Training for the intervention group}

In addition to the simulation cases with reflective debriefings, which were the same as those provided in the control group, the intervention group were given a web-based educational programme (phase I), and two reflection sessions that focused on SA (phase II and phase III) (Fig. 2 and Supplementary Table 1).

\section{Phase I}

One week before session two, the participants in the intervention group went through a one-hour webbased educational programme. The programme consisted of four brief video lectures, three reflective questions to process the content, and five multiplechoice questions at the end. The theoretical parts focused on how to achieve SA. The programme also included theory on interprofessional teamwork, patient safety, NTSs and reflective learning. The learning objectives were focused on: (1) human factors and their significance for clinical practice [23, 24]; (2) theories on how team members can optimize their abilities and identify their own strengths and weaknesses [25-27], (3) descriptions for understanding SA [7]; and (4) theories on how to use SA knowledge in clinical practice $[6,28]$. Each participant had an individual $\log$ in, which permitted personalized reminders to complete the programme.

Illustrations and a process description of SA were used with permission from Situational Awareness and Patient Safety, a resource developed by the Canadian Medical Protective Association and the Royal College of Physicians and Surgeons of Canada [28].

\section{Phase II}

Immediately before session two, the intervention group had a one-hour instructor-facilitated reflective discussion on the key concepts from phase I.

\section{Phase III}

After case 1 in session two, the participants had a reflective debriefing session [29] in a nearby room together with the instructors. The different phases of reflection - namely, reaction, analysis, summary and application - were discussed in order to facilitate experiential learning [22]. For the intervention group, the focus was on SA and how to turn theory into practice.

Finally, the participants were introduced to case 2 and were urged to apply their knowledge of SA and team skills.

\section{Training for the control group}

For the control group, the web educational programme (phase I) and the two reflection sessions (phases II and $I I I$ in the intervention) were not included in the training. However, after case 1, in session two, the control group had a debriefing session that included the same didactic as that provided to intervention group, except that it did not focus on SA (Table 1 and Supplementary Table 1).

\section{Data collection}

In order to evaluate the SA educational programme, questionnaires and video recordings of cases 0,1 and 2 were used. The questionnaires included background characteristics and the Situation awareness global assessment technique (SAGAT) (cases 1 and 2), the TEAM instrument and the $\mathrm{ABCDE}$ checklist (cases 0, 1 and 2; Figs. 2 and 3).

\section{SAGAT}

Within healthcare, the SAGAT is the most commonly used method to measure SA [30, 31]. Its feasibility within a Swedish context has been tested by our research group [32]. SAGAT was designed to measure three levels of SA: (1) perception, (2) comprehension, and (3) projection. SAGAT uses goal-directed task analysis, as initially described by Endsley [11], to develop SA items for each level. Major goals for the session are identified by expert and the questions are thereafter constructed to the specific SA recruitments. (Supplementary Table 2). The technique involves a "freezing" activity at set points during the simulation; during the freezing activity, the SAGAT questionnaires should be distributed to the participants [11]. In case 1 , a questionnaire with 13 items were distributed to the participants around 5 mins into the scenario. In case 2, 26 items were split into two different questionnaires, with the first "freeze" including 14 items and the second freeze including 12 


\section{Case 1}

Scenario

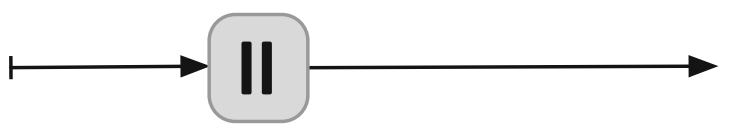

Measurements

TEAMS

$A B C D E$

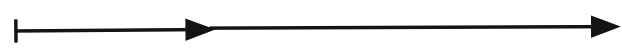

SAGAT

II

Scenario

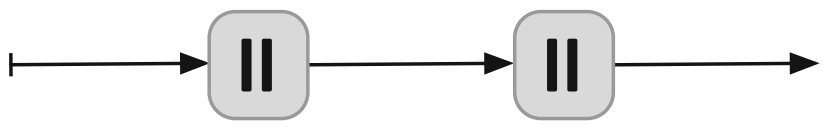

\section{Measurements}

TEAMS

$A B C D E$

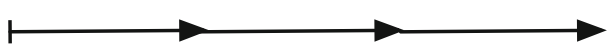

SAGAT

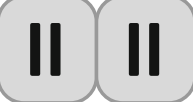

Fig. 3 Flow chart describing when measurements were used during cases 1 and 2

items. The first freeze occurred 5 mins into the scenario and the second freeze took place 5 mins after the scenario resumed. During the freeze times, the patient monitor was switched off. The items were either free text or multiple-choice items (Supplementary Table 2 and 3). The answers given by the participants were classified as either incorrect (0) or correct [1] by two of the authors $(\mathrm{KJ}, \mathrm{MHu})$. Individual SAGAT scores were calculated as the sum of the items and then team SAGA $\mathrm{T}$ (TSAGAT) was calculated as the mean score in each team, giving a TSAGAT between $0.00-13.00$ in case 1 and $0.00-26.00$ in case 2 .

\section{The TEAM instrument}

The TEAM instrument was used to measure team performance [33]. The TEAM instrument includes three subscales: leadership (2 items), teamwork (7 items), and task management ( 2 items), and includes one item for the assessment of overall performance. All items except for the overall item were scored on a scale from 0 to 4 (Never/Hardly ever $=0$, Seldom $=1$, About as often as not $=2$, Often $=3$, Always $/$ Nearly always $=4$ ), and overall was scored from 1 to 10 . Based on items in the respective subscale, mean scores were calculated for leadership, teamwork, and task management and given values between 0.00-4.00. In addition, based on all the items in the TEAM instrument $(n=11)$, a mean score was calculated (total) and given values between 0.00-4.00. Thus, the total score included all items measuring leadership, teamwork, and task management. The overall team performance item only consisted of one question and was therefore handled as a single overall item (overall) [33].

\section{ABCDE checklist}

The ABCDE checklist was developed out of the ATLS protocol [34], and the checklist has been tested for feasibility and interrater reliability by our research group [32]. In this study, the ABCDE checklist [32] was used 
to measure task performance in terms of how the teams managed the airway (one item), breathing (five item), circulation (two items), disability (one item) and exposure (one item), for a total of 10 items. Each item was scored from 0 to 3 (Not initiated $=0$, Performed partly $=$ 1 , Performed completely $=2$, Performed consistently during the whole simulation $=3$, Not applicable $=N A$ ). Based on all the items in the scale, a mean score was calculated, and a score from 0.00 to 3.00 was given. One item from breathing assessments was deleted in case 1.

Two of the authors ( $\mathrm{MHu}$ and MHä) independently reviewed the recorded videos and scored the TEAM instrument and the ABCDE checklists, blinded to the control and intervention group.

\section{Statistical analyses}

Statistical analysis was performed using IBM SPSS Statistics for Windows v.25. Background characteristics were described at the individual and team level (Table 1). At the individual level, age and prior work experience were presented as means and standard deviation. At the team level, the variables were aggregated, giving mean values for age and prior work experience. The remaining variables were binary, and mean values were used to show the proportion of participants in the teams belonging to the indicator category. For analyses of differences in background characteristics, independent sample $t$-tests or the Chisquare test were used, as indicated in Table 1.

According to the aim of this study, each team was defined as a unit. The means of the individuals in each team for each scale (TSAGAT, ABCDE and TEAM) were used as dependent variables. Normality for each dependent variable was checked with skewness.

The effect of the intervention on education was analysed with the generalized estimating equation (GEE) [35], assuming a scale linear model with an independent correlation matrix. The models accounted for the testing between the intervention and control group, the time (case 0 , case 1 and case 2) and changes over time between the intervention and control group. We used GEE models to analyse the changes from case 0 to case 2, and from case 1 to case 2, respectively. Significance was set at $p<0.05$.

\section{Study sample}

Calculation of statistical power for the TEAM instrument was performed to determine the number of participants using G*Power [36]. From previously published data (Table 3 in Cooper et al. [33]) a mean TEAM total of 2.49 with a standard deviation of 0.91 was calculated. With a power of $80 \%$ at the 0.05 significance level, a total of 22 teams would be needed to detect an increase in the mean of 1.0.

\section{Results}

In this randomized study, no significant differences were found in background characteristics between the intervention and control group regarding education, former crisis resource management (CRM) knowledge, former team training or proportion of MDs being specialists. The only significant difference between the groups was former courses at a team level $(p=0.041$; Table 1$)$.

After education in SA, the TEAM subscales leadership and task management as well as the total score improved significantly in the intervention group from case 1 to case 2 , as compared with the control group ( $p=$ $0.003, p=0.018$ and $p=0.030$; Table 2). More specifically, in the intervention group, the mean value for the subscale leadership increased from case 1 to case 2 (2.67, SE .11 vs. 3.17, SE .10), while there was no corresponding increase in the control group (2.50, SE .12 vs. 2.59, SE .11). The mean value for the subscale task management increased between case 1 and case 2 for the intervention group (2.50, SE .11 vs. 3.12, SE .07) and the corresponding increase for the control group was lower (2.60, SE .08 vs. 2.85, SE.14). The mean value for total increased between case 1 and case 2 for the intervention group (2.50, SE .08 vs. 2.91, SE .08), while the corresponding increase for the control group was somewhat lower (2.47, SE.08 vs. 2.70, SE .10; Table 2).

No significant differences were found between the intervention and control group in the TEAM subscales teamwork and overall, the TSAGAT or the ABCDE checklist (Table 2).

\section{Discussion}

This randomized controlled intervention study demonstrates improvements in team performance for intensive care teams after a 2-h, three-phase educational intervention with a focus on SA. Both the intervention and the control group participated in three full-scale simulation scenario training cases with debriefings. The intervention group increased its TEAM total score from case 1 to case 2, mainly due to improvements in the subscales leadership and task management.

This study builds on prior research indicating that team training improved team performance [37] and that well-functioning task work was found to be essential for efficient teamwork [38]. Frequent sharing of mental models and frequent back up team leader behaviour correlated to better team performance [18]. SA has been found to be essential when developing mental models [39], and simulation based education has been shown to be an effective learning modality to enhance SA [17]. Moreover, in a qualitative study ICU nurses described that simulation based team training will prepare ICU nurses in taking care of severely ill patients and achieve a more common understanding in teamwork towards 


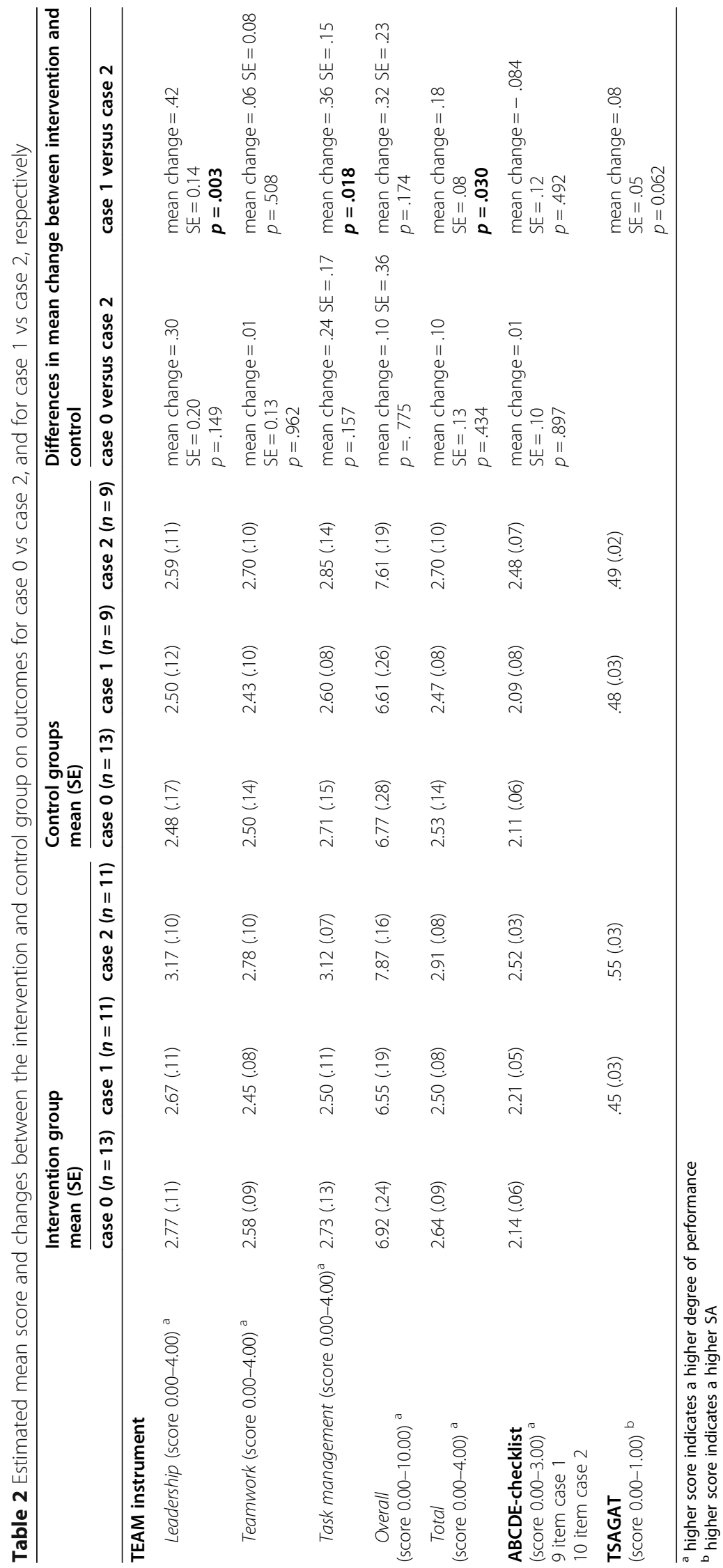


patient safety [40]. Thus, the intervention in this study was designed to facilitate a process where the multidisciplinary team, consisting of a mixture of competences and professions, work together to enhance their performance. In the present study we found an effect of the intervention on team performance but not did not find an effect on SA as measured by SAGAT. In a randomized trial, Hänsel et al. [41] studied the effect of simulation training compared to traditional CRM course on team performance and SA. In the group that received simulator training, SA (as measured by SAGAT) increased compared to the group participating in a traditional CRM course. A systematic review comparing the effectiveness of educational interventions on healthcare professionals' SA, showed that simulation based education as the most effective educational modality to enhance SA. However, of 39 included studies, only four had educational interventions specifically focusing on SA. In the other included studies, SA was only a small part of the educational intervention [17]. Thus, further research on the effects of educational interventions specifically focusing on SA is needed.

It is not a common practice in the literature to use the SAGAT to measure SA in ICU scenarios [42]. Cooper et al. [43] identified 14 studies measuring SA in emergency settings; of these, four used the SAGAT, but not in an ICU context. Recently, Coolen et al. [44] showed a correlation between the SAGAT, team task prioritization, problem solving and rapid diagnosis within paediatric acute care teams. In the present study, training in SA improved the professionals' abilities to manage critical situations, as measured with the TEAM instrument; however, the difference in mean change in the TSAGAT between the control and intervention group did not reach a significant level.

The limitations in this study require consideration. The SAGAT is measured by asking participants to answer questionnaires while the running scenario has been paused. Like all tests, SAGAT sensitivity is affected by small samples and few items [42]. It is possible that the relatively low number of items (13 in case 1 and 26 in case 2) might explain the lack of a significant difference in the SAGAT for the intervention group, as a greater number of items in the questionnaires might have increased the sensitivity of the SAGAT measurements.

A two-hour intervention might be considered as small compared to the effect size postulated in the power analysis. When planning the study, our assumption was that the educational intervention would have the potential to substantially increase TEAM performance. This brief, but systematic, training in enhancing SA did result in significant improvements in TEAM total, and in the subscales leadership and task management. Most likely, however, more teams would have been beneficial to enhance the power of the study. For example, the difference in SAGAT between intervention and control was borderline to becoming significant ( $p$-value 0.06 ), which might be a type II error.

Running full-scale in situ simulations in a critical care ward was challenging since resources might be dynamically reallocated from the educational programme to meet urgent clinical needs. It is well established that efficient team training requires effort $[45,46]$, and there is an association between learning outcomes and hours of training [47]. Repeated training sessions are needed for the retention of team training knowledge [45], as well as to achieve positive effects through CRM training [48].

This randomized controlled intervention study demonstrates that a small educational intervention, consisting of a web module with follow-up group discussion in preparation for an in situ simulation session, may increase the positive effects of simulation based education. As Parush [49] describes, SA is a tacit viable concept, highly relevant in the clinical context since specific SA education effect task as well as team performance and to achieve high SA is a trainable skill for both novices and well experienced staff. Focusing on obtaining SA - that is, the process of how the team as a whole notice the situation (perception), understands how to interpret the situation (comprehension) and realizes how the situation is about to develop (projection) - was found to increase team performance. It is still too early to draw definitive conclusions based available studies regarding which educational intervention that is most effective for optimizing team SA. Simulation as an educational modality is beginning to be evaluated favourably for healthcare [17], but still details as length of the intervention, repetitions, and team sizes remains elusive.

\section{Conclusion}

This study stresses the importance of education in SA in intensive care teams in order to improve team and task performance. SA influence mental models and is a precursor in decision-making and is therefore necessary for team coordination and performance. This study found improvements in the TEAM subscales leadership and task management after a 2-h educational intervention focusing on SA. The predicted increase in SA was not detectable, at least not with SAGAT. Randomized controlled educational in situ simulation studies are resource intensive but are needed to achieve evidence-based education. Further research is required to evaluate whether enhancing team SA can effectively improve team performance.

\section{Abbreviations}

CCRN: Critical care nurses; EN: Enrolled nurses; GEE: Generalized estimating equation; ICU: Intensive care units; MD: Physicians; NTS: Non-technical skill; SA: Situation awareness; SAGAT: Situation awareness global assessment technique; TSAGAT: Team situation awareness global assessment technique 


\section{Supplementary Information}

The online version contains supplementary material available at https://doi. org/10.1186/s13049-021-00878-2.

Additional file 1: Supplementary Table 1. Overview of differences in the educational programme between the control and intervention group. Supplementary Table 2. Goal directed task analysis document case 2. Supplementary Table 3. SAGAT questionnaire case 2, freeze one and two.

\section{Acknowledgements}

The authors wish to thank all the participating staff, simulator instructors and the organization from the two hospitals.

\section{Trial registration}

The ICMJE guidelines states that research on healthcare providers should be registered if the purpose is to examine health outcomes on patients but not if the purpose is to examine effects only on providers knowledge and attitudes. In our case we measure effects on providers knowledge and teamwork. No patients, except for a simulator, were involved in the study. Thus the study has not been prospectively registered.

\section{Authors' contributions}

All authors agree with the content and give consent to submit, also obtained consent from each institute where the work has been carried out. All author contributed to the study conception and design. Material preparation and the first draft of the manuscript were performed by Karin Jonsson and Magnus Hultin. All authors have read and approved the version to be published and agree that the work is appropriately investigated and resolved.

\section{Funding}

This study was made possible by support by Region Västerbotten, grant no. VLL-663801, VLL-836931, and RVB- 930528, by Region Norrbotten grant no NLL-765981, by J C Kempe memorial foundation, by Alice Lindstöm's foundation and by the Medical Faculty of Umeå university. Open Access funding provided by Umea University.

\section{Availability of data and materials}

The dataset used and analyzed during the current study are available from the corresponding author on reasonable request.

\section{Declarations}

\section{Ethics approval and consent to participate}

Approval was obtained from the Regional Ethical Review Board in Northern Sweden (April 7, 2016, Decision No. 2016-54-31 M). The study was performed in line with the principles of the Declaration of Helsinki. Written informed consent was obtained from all participants included in the study.

\section{Consent for publication}

Not applicable.

\section{Competing interests}

None of the authors have any support from company or have financial interest that may be relevant to the submitted work. All have completed the conflict of interest disclose statement.

\section{Author details}

'Department of Nursing and Department of Surgical and Perioperative Sciences, Anesthesiology and Critical Care Medicine, Umeå University, S-901 87 Umeå, Sweden. ${ }^{2}$ Department of Nursing, Umeå University, S-901 87 Umeå, Sweden. ${ }^{3}$ Department of Epidemiology and Global Health, Umeå University, S-901 87 Umeå, Sweden. ${ }^{4}$ Department of Surgical and Perioperative Sciences, Anesthesiology and Critical Care Medicine, Umeå University, S-901 87 Umeå, Sweden.
Received: 13 October 2020 Accepted: 21 April 2021

Published online: 02 June 2021

\section{References}

1. Nilsson L, Pihl A, Tagsjo M, Ericsson E. Adverse events are common on the intensive care unit: results from a structured record review. Acta Anaesthesiol Scand. 2012;56(8):959-65.

2. Garrouste-Orgeas M, Flaatten $H$, Moreno R. Understanding medical errors and adverse events in ICU patients. Intensive Care Med. 2016;42(1):107-9.

3. Merino P, Alvarez J, Cruz Martin M, Alonso A, Gutierrez I, Investigators SS. Adverse events in Spanish intensive care units: the SYREC study. Int J for Qual Health Care. 2012;24(2):105-13.

4. Reader TW, Flin R, Cuthbertson BH. Team leadership in the intensive care unit: the perspective of specialists. Crit Care Med. 2011;39(7):1683-91.

5. Donovan AL, Aldrich JM, Gross AK, Barchas DM, Thornton KC, Schell-Chaple $\mathrm{HM}$, et al. Interprofessional care and teamwork in the ICU. Crit Care Med. 2018;46(6):980-90.

6. Schulz CM, Endsley MR, Kochs EF, Gelb AW, Wagner KJ. Situation awareness in anesthesia: concept and research. Anesthesiol. 2013;118(3):729-42.

7. Endsley MR, Garland DJ. Situation awareness : analysis and measurement. Mahwah, NJ: Lawrence Erlbaum Associates; 2000.

8. Endsley MR, Jones DG. Designing for situation awareness : an approach to user-centered design. 2nd ed. Boca Raton, FL: CRC Press; 2012.

9. Brennan PA, Holden C, Shaw G, Morris S, Oeppen RS. Leading article: What can we do to improve individual and team situational awareness to benefit patient safety? Br J Oral \& Maxillofacial Surg. 2020;58(4):404-8.

10. Stout RJ, Cannon-Bowers JA, Salas E, Milanovich DM. Planning, shared mental models, and coordinated performance: an empirical link is established. Hum Factors. 1999;41(1):61-71.

11. Endsley MR. Toward a theory of situation awareness in dynamic-systems. Hum Factors. 1995;37(1):32-64.

12. D'Esmond LK. What was I thinking? Decision making and its impact on outcomes, quality improvement, and research. Intensive and Crit Care Nurs. 2018:45:1-2.

13. Nemeth CP. Improving healthcare team communication: building on lessons from aviation and aerospace. London: Routledge; 2017.

14. O'hare AJ, Beer A. A mixed method investigation of past trainees' perceptions of a critical incident situational awareness training program. J Police Crim Psychol. 2018;35(1):13-34.

15. Pons Lelardeux C, Panzoli D, Lubrano V, Minville V, Lagarrigue P, Jessel J-P. Communication system and team situation awareness in a multiplayer realtime learning environment: application to a virtual operating room. Vis Computer. 2017;33(4):489-515.

16. Brady PW, Goldenhar LM. A qualitative study examining the influences on situation awareness and the identification, mitigation and escalation of recognised patient risk. BMJ Quality Saf. 2014;23(2):153-61.

17. Walshe NC, Crowley CM, O'Brien S, Browne JP, Hegarty JM. Educational Interventions to Enhance Situation Awareness: A Systematic Review and Meta-analysis. Simul Healthc: J of the Society for Simul in Healthc. 2019; 14(6):398-408

18. Johnsen BH, Westli HK, Espevik R, Wisborg T, Brattebo G. High-performing trauma teams: frequency of behavioral markers of a shared mental model displayed by team leaders and quality of medical performance. Scand J Trauma Resusc Emerg Med. 2017;25(1):109.

19. Flin R, Patey R. Improving patient safety through training in non-technical skills. BMJ. 2009:339:b3595.

20. Schulz CM, Burden A, Posner KL, Mincer SL, Steadman R, Wagner KJ, et al. Frequency and type of situational awareness errors contributing to death and brain damage: a closed claims analysis. Anesthesiol. 2017;127(2):326-37.

21. Jonsson K, Hultin M, Härgestam M, Lindkvist M, Brulin C. Factors influencing team and task performance in intensive care teams in a simulated scenario. Simul in Healthc. 2020. Accepted for publication.

22. Kolb AY, Kolb DA. Learning styles and learning spaces: enhancing experiential learning in higher education. Acad Manag Learn Edu. 2005;4(2): 193-212.

23. Rall M, Dieckmann P. Safety culture and crisis resource management in airway management: general principles to enhance patient safety in critical airway situations. Best Pract Res Clin Anaesthesiol. 2005;19(4):539-57.

24. Odell M. Human factors and patient safety: changing roles in critical care. Aust Crit Care. 2011;24(4):215-7. 
25. Flin RH, O'Connor P, Crichton M. Safety at the sharp end: a giude to nontechnical skills. Hampshire: Ashgate Publishing; 2008.

26. Mohammed S, Michael A. West and Lynn Markiewicz. Building Team-Based Working: a Practical Guide to Organizational Transformation: WileyBlackwell; 2004.

27. Salas E, Shuffler ML, Thayer AL, Bedwell WL, Lazzara EH. Understanding and improving teamwork in organizations: a scientifically based practical guide. Hum Resour Management. 2015;54(4):599-622.

28. Quality AfHRa. Situational awareness and patient safety: a learning package. 2011 Available from: https://psnet.ahrq.gov/resources/resource/23606/situa tional-awareness-and-patient-safety-a-learning-package. (accessed 20 Sept 20).

29. Rudolph JW, Simon R, Rivard P, Dufresne RL, Raemer DB. Debriefing with good judgment: combining rigorous feedback with genuine inquiry. Anesthesiol Clin. 2007;25(2):361-76.

30. Wright MC, Taekman JM, Endsley MR. Objective measures of situation awareness in a simulated medical environment. BMJ Qual Saf. 2004;13(Suppl 1)::65-71.

31. Crozier MS, Ting HY, Boone DC, O'Regan NB, Bandrauk N, Furey A, et al. Use of human patient simulation and validation of the team situation awareness global assessment technique (TSAGAT): a multidisciplinary team assessment tool in trauma education. J Surg Educ. 2015;72(1):156-63.

32. Hultin M, Jonsson $\mathrm{K}$, Hargestam $\mathrm{M}$, Lindkvist $\mathrm{M}$, Brulin C. Reliability of instruments that measure situation awareness, team performance and task performance in a simulation setting with medical students. BMJ Open. 2019; 9(9):e029412.

33. Cooper S, Cant R, Porter J, Sellick K, Somers G, Kinsman L, et al. Rating medical emergency teamwork performance: development of the TEAM emergency assessment measure (TEAM). Resuscitation. 2010;81(4):446-52.

34. American College of Surgeons Committee on Trauma. Advanced trauma life support (ATLS(R)): the ninth edition. J Trauma Acute Care Surg. 2013;74: 1363-6.

35. Zeger SL, Liang KY. Longitudinal data analysis for discrete and continuous outcomes. Biometrics. 1986;42(1):121-30.

36. Faul F, Erdfelder E, Lang AG, Buchner A. G*power 3: a flexible statistical power analysis program for the social, behavioral, and biomedical sciences. Behav Res Methods. 2007;39(2):175-91.

37. Orledge J, Phillips WJ, Murray WB, Lerant A. The use of simulation in healthcare: from systems issues, to team building, to task training, to education and high stakes examinations. Curr Opin Crit Care. 2012;18(4):326-32.

38. Salas E, Rosen MA. Building high reliability teams: progress and some reflections on teamwork training. BMJ Qual Saf. 2013;22(5):369-73.

39. Endsley MR. The role of situation awareness in naturalistic decision making. Zsambok, C.E., \& Klein, G. (Eds.). (1997). Naturalistic Decision Making (1st ed.). Psychology Press. https://doi.org/10.4324/9781315806129.

40. Ballangrud R, Hall-Lord ML, Persenius M, Hedelin B. Intensive care nurses' perceptions of simulation-based team training for building patient safety in intensive care: a descriptive qualitative study. Intensive Critical Care Nurs. 2014;30(4):179-87.

41. Hansel M, Winkelmann AM, Hardt F, et al. Impact of simulator training and crew resource management training on final-year medical student's performance in sepsis resuscitation: a randomized trial. Minerva Anestesiol. 2012;78(8):901-9.

42. Endsley MR. A systematic review and meta-analysis of direct objective measures of situation awareness: a comparison of SAGAT and SPAM. Hum Factors. 2021:63(1):124-50.

43. Cooper S, Porter J, Peach L. Measuring situation awareness in emergency settings: a systematic review of tools and outcomes. Open Access Emerg Med. 2014;6:1-7.

44. Coolen E, Draaisma J, Loeffen J. Measuring situation awareness and team effectiveness in pediatric acute care by using the situation global assessment technique. Eur J Pediatr. 2019;178(6):837-50.

45. Ericsson KA. Deliberate practice and acquisition of expert performance: a general overview. Acad Emerg Med. 2008;15(11):988-94.

46. Stocker M, Allen M, Pool N, De Costa K, Combes J, West N, et al. Impact of an embedded simulation team training programme in a paediatric intensive care unit: a prospective, single-Centre, longitudinal study. Intensive Care Med. 2012;38(1):99-104.

47. McGaghie WC, Issenberg SB, Cohen ER, Barsuk JH, Wayne DB. Does simulation-based medical education with deliberate practice yield better results than traditional clinical education? A meta-analytic comparative review of the evidence. Academic Emerg Med. 2011;86(6):706-11.

48. Pruitt CM, Liebelt EL. Enhancing patient safety in the pediatric emergency department: teams, communication, and lessons from crew resource management. Pediatr Emerg Care. 2010;26(12):942-8 quiz 9-51.

49. Parush A. Situational awareness: a tacit yet viable concept. Can J Anesth. 2017;64(8):797-800.

\section{Publisher's Note}

Springer Nature remains neutral with regard to jurisdictional claims in published maps and institutional affiliations.
Ready to submit your research? Choose BMC and benefit from:

- fast, convenient online submission

- thorough peer review by experienced researchers in your field

- rapid publication on acceptance

- support for research data, including large and complex data types

- gold Open Access which fosters wider collaboration and increased citations

- maximum visibility for your research: over $100 \mathrm{M}$ website views per year

At BMC, research is always in progress.

Learn more biomedcentral.com/submissions 